\title{
batllot
}

\section{A nocividade da reforma eleitoral}

\section{Lenine Póvoas (PUC-SP, Brasil)}

lenine@povoasdeabreu.adv.br

Av. Historiador Rubens de Mendonça, No 1.731

Ed. Centro Empresarial Paiaguás - CJ. 507 - CEPः 78050-000 


\title{
Resumo
}

Trata-se de artigo visando demonstrar que a Reforma Política (Lei no 13.165/2015) trará muito mais malefícios do que benefícios à democracia, uma vez que a redação da Legislação está voltada para a perpetuação dos agente políticos já conhecidos no Poder. Os métodos utilizados serão o dedutivo e o sociológico, e, de forma auxiliar, o sistêmico, lógico, histórico e finalístico, objetivando demonstrar que o discurso de redução do tempo de campanha, utilizado para elaboração da norma, não irá baratear as eleições e nem tampouco barrar a influência do poder econômico no certame. Além disso, a minimização do período eleitoral dificulta um debate mais aprofundado entre o agente político e os eleitores no que se refere aos problemas sociais, impossibilitando o surgimento de novas bandeiras e lideranças. A Reforma Política não alterou a estrutura do Poder Público e nem tampouco atenderá as prioridades e necessidades da sociedade, de modo que ainda trará grande problemática na questão da legitimidade da representação popular.

Palavras-chaves: Reforma Política; Redução dos Custos; Influência do Poder Econômico; Malefícios; Perpetuação dos Agentes Políticos Conhecidos no Poder; Impossibilidade de Oxigenação de Lideranças Políticas

\section{The Harmful Aspects of Electoral Reform}

\begin{abstract}
This is article aimed to demonstrate that the Political Reform (Law No. 13,165 / 2015) will bring more harm than good to democracy, since the wording of the legislation is focused on the perpetuation of the political agent known in Power. The methods used will be the deductive and the sociological, and auxiliary form, systemic, logical, historical and finalistic, aiming to demonstrate that the reduction of speech campaign time, used for the preparation of the standard, will not cheapen the elections and not either stop the influence of economic power in the event. In addition, minimizing the election period hinders further discussion between the political agent and voters with regard to social problems, preventing the emergence of new brands and leaders. The Political Reform did not change the structure of government and neither meet the priorities and needs of society, so that will bring big problems in the question of the legitimacy of popular representation.
\end{abstract}

Keywords: Political Reform; Reduce Costs; Effect of Economic Power; Harm; perpetuation of the political agents Known in Power; Impossibility of oxygenation Leadership Policies 
O Direito Eleitoral atraí uma peculiaridade que as demais matérias do cenário legal não envolvem: o legislador é o direto destinatário da norma.

Assim, é muitíssimo provável que o parlamentar, no momento de elaboração do texto legal, tende a se inclinar em uma normativa que lhe favoreça.

Ocorre que essa situação, atrelada ao contexto histórico da formação do patronato político brasileiro, desencadeia uma série de fenômenos dentro do ordenamento pátrio.

Tanto é assim que, volta e meia, visando atingir determinados benefícios pessoais e/ou de uma certa agremiação, o Congresso elabora a legislação eleitoral a mercê da Constituição da República, o que acaba justificando o grande número de Ações Diretas de Inconstitucionalidade no Supremo Tribunal Federal por parte daqueles que se sentem lesionados ou até mesmo do Ministério Público.

Nessa toada, não se pode perder de vista que, sociologicamente, a população brasileira sempre carregou consigo o gosto amargo da suposta exploração aética do Poder Público perante a sociedade.

Cingindo-se dessas premissas, em 2013, a sociedade civil saiu as ruas do país, protestando à respeito da forma com que a República era conduzida, exigindo, portanto, uma Reforma dentro deste cenário. Todavia, não havia bandeiras e nem tampouco reivindicações precisas, o que acabou dispersando um pouco o movimento no que tange a coalizão dos interesses postulados.

Tempos depois, uma minoria das vozes das ruas clamavam por uma alteração legislativa referente a maneira de eleger os representantes, enquanto a parcela majoritária exigia a saída de determinadas figuras públicas do cenário político.

É importante fazer distinção entre essas duas situação, uma vez que a maioria das pessoas queriam uma mera Reforma na Política (alteração dos representantes do povo), já outros solicitavam uma Reforma Política (alteração do sistema político no que concerne a forma de eleger os representantes).

Pressionado, o Congresso Nacional passou a discutir a Reforma Política, a qual foi concluída e sancionada por intermédio da Lei no 13.165/2015 e será aplicada no pleito de 2016.

Em que pese não tenha ocorrido, o diálogo com a sociedade é sempre importantíssimo, de modo que isso possibilita ao legislador conhecer os anseios da população, vislumbrando possíveis alternativas aptas a resolverem os problemas sociais. Todavia, esse processo é extremamente moroso e oneroso, o que acaba dificultando uma discussão mais ampla e profunda.

Ademais, considerando que o legislador elabora a Lei para ele mesmo, pode haver falta de interesse, intencional ou não, por parte de classe política em debater essa matéria com a sociedade e com especialistas no tema.

O principal argumento que, principiologicamente, direcionou a nova legislação foi a redução dos gastos eleitorais, cujo entendimento veio à cabo após a decisão do Supremo Tribunal Federal proibindo doação de recursos de pessoas jurídicas para candidatos em pleitos futuros (ADI 4650).

Antes de adentrar ao teor da Reforma, há de se salientar que no cenário político não existem "sistemas de governos perfeitos", mesmo porque todos apresentam aspectos positivos e negativos. Com isto, é necessário fazer uma escolha dentre as opções que encontram amparo no ordenamento jurídico e avaliar aquela que vai melhor se adaptar a estrutura e a realidade sócio-político-econômico local, ou seja, aquela que possua mais bônus do que ônus no que tange a legitimidade das eleições e a solução dos conflitos da sociedade. 


\section{A Reforma Política (Lei no 13.165/2015)}

A Reforma Política foi recebida no meio jurídico com muita preocupação, uma vez que houve enorme retrocesso em inúmeros aspectos da Legislação Eleitoral, configurando enorme prejuízo à Democracia, mormente por ter mais ônus do que bônus, cujos benefícios possivelmente foram previamente direcionados àqueles que já estão no Poder.

O que a Lei no 13.165/2015 trouxe foi uma alteração nas regras dos pleitos ("Reforma Política") com objetivos político-eleitoreiros.

Dentre os inúmeros pontos que sofreram alterações, destacam-se os seguintes: (i) financiamento de campanha; (ii) redução do tempo de campanha; (iii) regulamentação da infidelidade partidária; (iv) eleições suplementares (quem assume no caso de cassação do Chefe do Poder Executivo), dentre outros.

\section{Financiamento de Campanha}

Como já mencionado, o STF vetou o financiamento de campanha por parte de pessoas jurídicas, cuja fundamentação se escorou, em suma, no fato de que a permissão de empresas em pleitos estaria criando uma plutocracia, máxime porque supostamente o Poder estaria sendo exercido pelos mais ricos, o que ceifava a legitimidade da representação popular.

Porém, há de se salientar que todos, pessoas físicas e jurídicas, são diretamente afetados pelas Políticas Públicas, de modo que é perfeitamente compreensível o interesse pessoal e empresarial nesses ou naqueles candidatos, o que legitima apoiar agentes políticos que defendam propostas alinhavadas as suas atividades, sem que, com isso, desvirtuem-se os propósitos democráticos.

Entretanto, o Supremo Tribunal Federal entendeu que, após se consagrarem vencedores no certames eleitorais, os agentes políticos faziam conchavos com as empresas que realizaram as doações para praticarem atos ilícitos com escopo em se locupletarem do erário público.

Todavia, retirar a responsabilidade dos corruptos e depositar no sistema é uma visão democrática paternalista, o que acaba infantilizando a República, sobretudo por se acreditar que os problemas dessa seara irão desaparecer com uma singela alteração legislativa, engessando um progresso num ritmo satisfatório.

O ideal seria uma normativa estipulando limites de gastos e doaçóes, tanto para pessoas físicas e jurídicas, bem como uma rígida fiscalização nesse sentido, não se olvidando da manutenção e rígida repreensão nos casos de descumprimento dos princípios norteadores da administração pública referente às contratações realizadas pelo Poder Público com as Pessoas Jurídicas.

Nesse sentido, embora esteja vedado as doações de pessoas jurídicas, o Tribunal Superior Eleitoral, por intermédio da Resolução $n^{\circ} 23.459 / 2015$, estipulou previamente o limite de gastos para os cargos de vereador e prefeito nas eleições municipais de 2016, o que pode reduzir a interferência do poder econômico no certame, o qual, atualmente, é apontado como um dos grandes fatores a contribuírem para a consagração da soberania popular.

Com efeito, referido posicionamento pode fazer acentuar a captação ilícita de recursos e gastos ilícitos ("caixa dois") ou a criação de um verdadeiro "laranjal" ('compra' de pessoas físicas para realizarem doações), tendo em vista que, dentro da atual conjectura, é impossível se fazer campanha sem recursos financeiros, haja vista a indispensabilidade de determinados profis- 
sionais e pessoas nos certames (marqueteiros, material de campanha, advogados, contadores, cabos eleitorais, estrutura de evento, carros, combustível, etc).

O atual posicionamento de vedação do Supremo no que tange a proibição de doações por parte de pessoas jurídicas poderá dar ensejo a conhecida frase: "dinheiro é como água, sempre acha uma saída".

\section{Redução do Tempo de Campanha}

Antigamente as campanhas eleitorais compreendiam o período de 90 dias, sendo que atualmente são meros 45 dias, isto é, houve uma redução de $50 \%$ do tempo sob a alegação de "redução de custos", visando, por conseguinte, rechaçar a influência do poder econômico, uma vez que quanto maior o período eleitoral, maior o gasto.

Essa tratativa refere-se a uma profunda mudança que, silenciosamente, está direcionada para resguardar os interesses daqueles que já se encontram investidos em cargos públicos, impossibilitando a oxigenação de novas lideranças políticas.

Evidentemente que quem já possuí o nome consolidado no cenário político se favorece caso haja restrição da possibilidades de divulgação de novas propostas (propagandas eleitorais), uma vez que isso cerceará o aparecimento e crescimento de novas lideranças e bandeiras.

Um dos maiores instrumentos da democracia é o debate (propaganda), sobretudo para que, dessa forma, seja possível que o candidato conheça os anseios populares e elabore suas propostas políticas. Entretanto, com a redução do tempo de campanha, torna-se mais dificultoso que novos candidatos e lideranças possam levar ao conhecimento da sociedade suas plataformas políticas, bem como acaba restringindo a possibilidade de um debate mais amplo acerca das dificuldades enfrentadas pela população e do sistema de eleição.

Importante registrar que tempos atrás as propagandas eram mais voltadas para ideologias partidárias, demonstrando as diretrizes de atuação e formas de governo das agremiações em caso de vitória nas urnas. Porém, hodiernamente, as propagandas são mais individualistas e voltadas para a imagem pessoal de cada candidato.

Nesse contexto (redução do tempo de campanha, inviabilizando a exposição de novas lideranças políticas, atrelado as propaganda voltadas para as características pessoais de cada candidato), a reforma política, sem sobra de dúvidas, beneficia os grandes partidos e aqueles que já são conhecidos da população, seja em virtude de atuação política ou midiática (artistas), máxime por já existir capilaridade entre eles.

Outro ponto que sofreu reflexo em virtude da diminuição do tempo de campanha foram os julgamentos dos registros de candidaturas. Atualmente a Justiça Eleitoral terá meros 28 dias para apreciar se os candidatos preenchem todos os requisitos de inelegibilidade e se incidem ou não em alguma cláusulas de inelegibilidade.

Evidentemente que esse lapso temporal é exíguo, razão pela qual muitas eleições ocorrerão subjudice, ou seja, sem que se saiba se determinados candidatos, juridicamente, estão aptos ou não a concorrem ao pleito, o que acabará impossibilitando o eleitor de conhecer de antemão se o seu voto será ou não validado após o trânsito em julgado de determinados registros de candidaturas, trazendo enorme insegurança e instabilidade. 
O mau uso da campanha não significa que ela deva ser proibida ou restringida, mas apenas e tão somente fiscalizada com mais afinco, sob pena de termos mais prejuízos do que benefícios democráticos.

Para elaborar uma legislação é necessário uma visão panorâmica da situação, a qual, por sua vez, não pode ser nivelada por baixo, isto é, por aqueles que cometeram ilícitos.

\section{Infidelidade Partidária}

Antigamente a infidelidade partidária era tratada por meio da Resolução $n^{\circ}$ 22.610/TSE, a qual autorizava mandatários a migrarem de sigla em caso de incorporação, fusão ou criação de partido, mudança substancial ou desvio de programa partidário e grave discriminação pessoal.

Insta salientar que o STF, no julgamento da Ação Direta de Inconstitucionalidade no 5081, de maio de 2015, sedimentou entendimento no sentido de que a infidelidade partidária somente era aplicada aos cargos do sistema proporcional (Vereadores, Deputados Estaduais, Deputados Federais e Deputados Distritais), portanto, não atingia os cargos em que os agentes fossem eleitos pelo sistema majoritário (Prefeitos, Governadores, Senadores e Presidente da República).

Após a Reforma Política, a matéria passou a ser regulamentada pela Lei dos Partidos Políticos (Lei no 9.096/95), a qual ratificou os entendimento já vigente, porém, restringiu a mudança de mandatários para partidos recém-criados, sob pena de perda do cargo.

Com isto, uma grei recentemente criada se sentiu lesada e pleiteou a declaração de inconstitucionalidade parcial da norma na parte em que proíbe a justa desfiliação partidária com supedâneo na criação de novo partido político (ADI no 5398). A medida cautelar ("liminar") foi deferida, possibilitando a mudança de mandatários para a nova sigla em 30 dias. $\mathrm{O}$ mérito ainda não foi apreciado.

Caso fosse mantida essa restrição, os partidos não conseguiriam atrair nenhum mandatário, mormente por não estarem acobertados pela justa causa de desfiliação, o que certamente ocasionaria a perda do cargo. Seriam partidos que nasceriam sem perspectivas.

Assim, pode-se extrair, perfunctoriamente, que vedar a mudança de mandatários para partidos recentemente criados é inconstitucional, cuja redação da lei pode assim ter sido intencionalmente elaborada para inviabilizar a criação de musculatura das agremiações novas.

A Lei no 13.165/2015 criou ainda uma nova permissão de mudança de partido, a qual ficou conhecida como "janela”. Esse instituto jurídico é o meio pelo qual o mandatário pode trocar de partido 30 dias antes do prazo de filiação exigido em lei ( 6 meses antes da eleição), ao término do mandato vigente.

\section{Eleições Suplementares}

Antes da Reforma, caso um candidato que tivesse obtido mais de $50 \%$ dos votos fosse cassado em matéria eleitoral, haveria necessidade de realização de novo pleito. Na hipótese do cassado ter obtido menos de $50 \%$ dos votos, o segundo colocado assumiria (antiga redação do art. 224 do Código Eleitoral). 
Atualmente, caso um candidato tenha o seu diploma cassado antes dos últimos seis meses de mandato, deverá ser realizada novas eleições, independentemente da quantidade de votos obtidos pelo agente consagrado nas urnas, ou, caso isso ocorra nos seis últimos meses de mandato, haverá eleição indireta. Em ambos os casos caberá à Justiça Eleitoral arcar com os gastos do novo pleito.

Entretanto, tal entendimento só é válido após o trânsito em julgado da demanda que postula a cassação do diploma, cujo empecilho poderá restringir a aplicabilidade invocada, mormente por ser inimaginável que um processo dessa magnitude se finde num prazo tão exíguo.

\section{Conclusões}

Diante da apertada síntese acima, pode-se observar que a Lei $n^{\circ}$ 135.165/2015 trouxe alguns malefícios democráticos que somente poderão ser constatados pela sociedade civil no decorrer dos anos, uma vez que o discurso sofista-edênico de "redução de gastos" na verdade tende a dificultar o surgimento de novas lideranças e a perpetuação dos agente políticos já conhecidos no Poder.

O fato é que não houve alteração na estrutura do Estado e nem tampouco atendimento nas prioridades e necessidades da população, sendo que a Reforma Política vai trazer muito mais problemas do que benefícios, inobstante ao fato de que não possibilitará uma maior legitimidade da representação popular.

Em virtude das inúmeras e corriqueiras alterações legislativas, instabilidades e conflitos de entendimentos jurisprudenciais, oxigenação de membros das cortes, turbulência econômicas e políticas, etc., torna-se claro que o país necessita muito mais de estabilidade do que de Reforma Política, sobretudo porque é uma grande ilusão achar que ela (Reforma Política) será capaz de resolver os problemas nacionais.

Democracia se faz com história. Existem inúmeras discussões orbitando no âmbito jurídico-eleitoral que já foram devidamente "testadas" no passado e restou demonstrado a sua total ineficácia a respeito dos objetivos almejados, cuja conclusão parece que passa desapercebida.

A estabilidade possibilita galgar projetos republicados que não sejam edificados sob areia movediça.

Um dos grandes males da Ditadura é a arbitrariedade, da Aristocracia é a oligarquia e o da Democracia é a demagogia. Tanto é assim que a diferença entre o Estadista e o Demagogo é que o Estadista se preocupa com as próximas geraçóes e o Demagogo com as próximas eleições. 


\section{Referências}

AGRA, Walber de Moura e Francisco Queiroz Cavalcanti- Comentários À Nova Lei Eleitoral - Ed. Forense - $1^{a}$ edição - 2010;

ALVIM, Frederico Franco - Curso de Direito Eleitoral - Ed. Juruá - 2014;

BAUMAN, Zygmunt - Em busca da Política - Editora Zahar;

BOBBIO, Norberto - O Futuro da Democracia - Editora Paz e Terra - 2012;

NETO, Pedro Sabino de Farias - Ciência Política - Editora Atlas;

TOCQUEVILE, Alexis de - A Democracia na América - Ed. Itatiaia Limitada - 4a Edição -1998 - Belo Horizonte; 
Recebido em: 23/01/2016

Aceito em: 11/03/2016

\section{Como citar}

PÓVOAS, Lenine. A nocividade da reforma eleitoral. Ballot. Rio de Janeiro: UERJ. Volume 2 Número 1 Janeiro/Abril 2016. pp. 236-244.

Disponível em: [http://www.e-publicacoes.uerj.br/index.php/ballot]

\section{(ब) $\odot(0$}

A Revista Ballot está licenciada sob uma licença Creative Commons Atribuição - Não Comercial - Compartilha Igual 3.0 Não Adaptada. 